DOI: 10.12731/2658-6649-2019-11-5-2-84-89

УДК 616.1

\title{
РАСПРОСТРАНЕННОСТЬ, ДИГНОСТИКА И ПСИХОЛОГИЧЕСКИЕ ОСОБЕННОСТИ ИЗБЫТОЧНОГО ВЕСА И ОЖИРЕНИЯ
}

\author{
Москаленко О.Л., Смирнова О.В., Каспаров Э.В.
}

В статье рассматривается проблема избыточного веса и ожирения среди взрослого населения, число которых увеличивается с каждым годом. По ВОЗ ожирение называют эпидемией или пандемией. У больных страдающих ожирением выявляются серьезные заболевания и ранняя смертность, также приводит к тревожным расстройствам, неврозоподобным состояниям и депрессиям.

Ключевые слова: ожирение; избыточный вес; осложнения; индекс массы тела.

\section{PREVALENCE, DIAGNOSIS AND PSYCHOLOGICAL PECULIARITIES OF EXCESS WEIGHT AND OBESITY}

Moskalenko O.L., Smirnova O.V., Kasparov E.V.

The article deals with the problem of overweight and obesity among adults, whose number is increasing every year. According to WHO, obesity is called an epidemic or pandemic. In obese patients, serious diseases and early mortality are detected, also leading to anxiety disorders, neurosis-like conditions and depressions.

Keywords: obesity; overweight; complications; body mass index.

По определению ВОЗ избыточный вес и ожирение - это увеличение массы тела за счет жировой ткани с отложением жира. В диагностики ожирения и избыточного веса используют самый простой и доступный метод - определение индекса массы тела, который вычисляют, отношением массы тела в килограммах к квадрату роста в метрах $\left(\kappa г / \mathrm{M}^{2}\right)$ : если

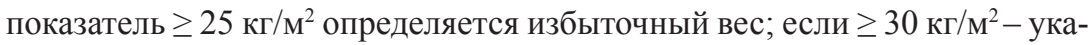
зывает на ожирение. 
Целью нашего исследования явилось изучение распространенности, диагностики и психологических особенностей избыточного веса и ожирения у взрослых, как фактора риска развития патологий, метаболических нарушений, заболеваний сердечно-сосудистой системы, нарушения опорно-двигательного аппарата и системы гемостаза. Также вероятность перечисленных заболеваний повышается с увеличением ИМТ.

\section{Материал и методы}

Представлен обзор исследований посвященных избыточному весу и ожирению с использованием поисковых систем научных публикаций в библиографических и реферативных базах данных Scopus, PubMed, MEDLINE, РИНЦ, Google Scholar с проведением анализа литературных данных. Обсуждаются современные подходы в диагностике, т.к. ожирение является серьезной медицинской, социальной и экономической проблемой.

\section{Результаты}

Согласно данным ВО3 по странам, в 2008 г. более 50,0\% у мужчин и женщин в Европе установлен избыточный вес и около 23,0\% женщин и 20,0\% мужчин - ожирение.

В России в 2017 г. пациентов с ожирением 5,4\% Алтайском крае, далее по регионам: Магаданская область, Курганская, Тюменская, Оренбургская области.

По результатам многочисленных и многолетних исследований, по изучению избыточного веса и ожирения, которые говорят о нарушении в психической сфере и влияют на развитие патологического пищевого поведения.

В исследовании Беляковой Н.А. с соавт. установлено, что у пациентов с избыточным весом и ожирением нарушение пищевого поведения связаны с образом жизни и психологическим статусом (склонность к стрессам), с наследственными факторами, что в дальнейшем отражается на качестве жизни (депрессии и тревоги).

Согласно имеющимся в литературе данным (Вахмистров А.В., Менделевич В.Д., Петров Д.П. и др.) о том, что в формировании избыточного веса и ожирения важным являются психологические факторы. Также к развитию ожирения могут приводить сниженная физическая активность, нарушение пищевого поведения (переедание).

В работе Колосницына М.Г., Бердникова А.Н. пациентов распределяли по уровню образования и полу для определения ИМТ. Так у женщин с 
высшим профессиональным образованием ожирение выявлялось в $18,0 \%$, а в группах с незаконченным или законченным средним (полным) общим 24,0-29,0\%. У мужчин с высшим профессиональным образованием установлен ИМТ выше нормы, т.е. определялся избыточный вес, ожирение.

\section{Выводы}

Таким образом, избыточный вес и ожирение распространены среди взрослого населения. Ожирение приводит к тревожным расстройствам, неврозоподобным состояниям и депрессиям, что в дальнейшем может приводить к ухудшению основного заболевания.

В связи с этим крайне важно оценивать проблему избыточного веса и ожирения у взрослых, неправильного питания и малоподвижного образа жизни и рассматривать в качестве приоритетной.

Информация о конфликте интересов. Авторы заявляют об отсутствии конфликтов интересов.

Информация о спонсорстве. Исследование не имело спонсорской поддержки.

\section{Список литературы}

1. Белякова Н.А. Пищевое поведение, образ и качество жизни, а также психологический статус больных с алиментарно-конституциональным ожирением / Н.А. Белякова, М.Б. Лясникова, Н.О. Милая // Сибирский медицинский журнал. 2014. № 2. С. 20-23.

2. Ожирение, как фактор риска сердечно-сосудистых заболеваний и патологических состояний, обусловленных избыточным весом. Москаленко О.Л., Смирнова О.В., Каспаров Э.В., Иванова Е.Б. В сборнике: Сложные системы в экстремальных условиях Материалы XIX Всероссийского симпозиума с международным участием. Федеральное государственное бюджетное научное учреждение «Федеральный исследовательский центр «Красноярский научный центр Сибирского отделения Российской академии наук». 2018. C. $147-149$.

3. Особенности полиморфизма генов PNPLA 3 (RS738409), TM6SF 2 (RS58542926), $M B O A T 7$ (RS641738), как способ диагностики иммунопатологии при жировом гепатозе. Москаленко О.Л., Смирнова О.В., Каспаров Э.В., Иванова Е.Б. Российский аллергологический журнал. 2018. Т. 15. № 1-2. С. 64-67.

4. Перспективные задачи оптимизации питания на основе современных методов оценки пищевого статуса и энерготрат. Васильев А.В., Манчук В.Т., 
Каспаров Э.В., Прахин Е.И. Вопросы детской диетологии. 2010. Т. 8. № 3. C. 44-46.

5. Grundy S.M. Obesity, metabolic syndrome, and cardiovascular disease. J.Clin. Endocrinol. Metab. 2004. V. 89, pp. 2595-2600.

6. Marchesini G., Forlani G., Cerrelli F. et al. WHO and ATP III proposals for the definition of the metabolic syndrome in patients with type 2 diabetes. Diabetic Medicine 2004. V.21, pp. 383-387.

\section{References}

1. Belyakova N.A., Lyasnikova M.B., Milaya N.O. Pishchevoe povedenie, obraz i kachestvo zhizni, a takzhe psihologicheskij status bol'nyh s alimentarno-konstitucional'nym ozhireniem [Nutritional behavior, image and quality of life, as well as the psychological status of patients with alimentary constitutional obesity]. Sibirskij medicinskij zhurnal [Siberian Medical Journal]. 2014.№ 2. S. 20-23.

2. Moskalenko O.L., Smirnova O.V., Kasparov E.V., Ivanova E.B. Ozhirenie, kak faktor riska serdechno-sosudistyh zabolevanij i patologicheskih sostoyanij, obuslovlennyh izbytochnym vesom [Obesity as a risk factor for cardiovascular diseases and pathological conditions caused by overweight]. V sbornike: Slozhnye sistemy v ekstremal'nyh usloviyah Materialy XIX Vserossijskogo simpoziuma s mezhdunarodnym uchastiem. Federal'noe gosudarstvennoe byudzhetnoe nauchnoe uchrezhdenie «Federal'nyj issledovatel'skij centr «Krasnoyarskij nauchnyj centr Sibirskogo otdeleniya Rossijskoj akademii nauk». 2018. S. 147-149.

3. Moskalenko O.L., Smirnova O.V., Kasparov E.V., Ivanova E.B. Osobennosti polimorfizma genov PNPLA 3 (RS738409), TM6SF 2 (RS58542926), MBOA T7 (RS641738), kak sposob diagnostiki immunopatologii pri zhirovom gepatoze [Features of the polymorphism of the PNPLA 3 genes (RS738409), TM6SF 2 (RS58542926), MBOA T7 (RS641738), as a way to diagnose immunopathology in fatty hepatosis]. Rossijskij allergologicheskij zhurnal [Russian allergological journal]. 2018. T. 15. № 1-2. S. 64-67.

4. Vasil'ev A.V., Manchuk V.T., Kasparov E.V., Prahin E.I. Perspektivnye zadachi optimizacii pitaniya na osnove sovremennyh metodov ocenki pishchevogo statusa i energotrat [Perspective problems of food optimization based on modern methods of assessing food status and energy consumption]. Voprosy detskoj dietologii [Questions of children’s nutrition]. 2010. T. 8. № 3. S. 44-46.

5. Grundy S.M. Obesity, metabolic syndrome, and cardiovascular disease. J.Clin. Endocrinol. Metab. 2004. V. 89, pp. 2595-2600.

6. Marchesini G., Forlani G., Cerrelli F. et al. WHO and ATP III proposals for the definition of the metabolic syndrome in patients with type 2 diabetes. Diabetic Medicine 2004. V.21, pp. 383-387. 


\section{ДАННЫЕ ОБ АВТОРАХ}

Москаленко Ольга Леонидовна, старший научный сотрудник, кандидат биологических наук Федеральное государственное бюджетное научное учреждение «Научно-исследовательский институт медицинских проблем Севера» ул. Партизана Железняка, 32, г. Красноярск, 660022, Российская Федераиия gre-ll@mail.ru ORCID: 0000-0003-4268-6568

Смирнова Ольга Валентиновна, д.м.н., профессор, заведующая лабораторией клинической патофизиологии Федеральное государственное бюджетное научное учреждение «Федеральный исследовательский центр «Красноярский научный иентр Сибирского отделения Российской академии наук» «Научно-исследовательский институт медицинских проблем Севера» ул. Партизана Железняка, 32, г. Красноярск, 660022, Российская Федераиия ovsmirnova71@mail.ru

Каспаров Эдуард Вильямович, д.м.н., профессор, директор НИИ МПС ФИЦ КНЦ СО РАН, зам. директора

Научно-исследовательский институт медиииских проблем Севеpa, Федеральное государственное бюджетное научное учреждение «Федеральный исследовательский иентр «Красноярский научный иентр Сибирского отделения Российской академии наук» ул. Партизана Железняка, 32, г. Красноярск, 660022, Российская Федераичия impn@impn.ru

\section{DATA ABOUT THE AUTHORS}

Moskalenko Olga Leonidovna Senior Researcher, Candidate of Biological Sciences

Federal State Budgetary Scientific Institution «Scientific Research Institute of medical problems of the North»

3g, Partizan Zheleznyaka str., Krasnoyarsk, 660022, Russian Federation gre-ll@mail.ru

ORCID: 0000-0003-4268-6568 
Smirnova Olga Valentinovna, MD, Professor, Head of the Laboratory of Clinical Pathophysiology

Scientific Research Institute of Medical Problems of the North 3g, Partizan Zheleznyaka Str., Krasnoyarsk, 660022, Russian Federation ovsmirnova71@mail.ru

Kasparov Eduard Vilyamovich, MD, Professor, Director

Scientific Research Institute of medical problems of the North, Federal Research Center "Krasnoyarsk Science Center» of the Siberian Branch of the Russian Academy of Sciences, Krasnoyarsk, Krasnoyarsk territory (krai), Russia

3d, Partizan Zheleznyaka Str., Krasnoyarsk, 660022, Russian Federation impn@impn.ru 